Comparative Philosophy Volume 11, No. 2 (2020): 140-156

Open Access / ISSN 2151-6014 / www.comparativephilosophy.org

https://doi.org/10.31979/2151-6014(2020).110209

\title{
RESPECT AND THE MENGZIAN CONCEPTION OF YI AS A RULE-RELATED VIRTUE
}

\author{
MENG ZHANG
}

\begin{abstract}
This paper focuses on Meng Zi's idea of yi (義) as a virtue. In it, I first briefly examine two influential interpretations of $\mathrm{yi}$ - the "appropriateness" approach that views yi as a disposition to do what is fitting in a given situation and the shame-centered approach that understands yi as a disposition to avoid what is shameful in the moral life. The first approach is too thin to distinguish yi from acting properly in general and the second reading confines the definitive feeling involved in yi to a too moralized understanding of shame. Moreover, both fail to pay enough attention to the reliance of yi on social norms to receive its content. Through textual analysis, I show that in addition to a sense of shame, respect as an attitude of prioritizing other persons in the way specified by the relevant norms also serves as an important emotional core of yi as a virtue. In the end, I highlight the potential contribution of the Mengzian idea of yi to virtue ethics. The two-faceted structure of yi points to a way to account for rule-related virtues - virtues that have rule-conformity as a component. Equipped with thick descriptions of rule-related virtues, virtue ethics will be in a better position to guide actions.
\end{abstract}

Keywords: yi, Meng Zi, respect, virtue ethics

This paper examines the virtue of $y i$ ("righteousness", "justice", "appropriateness", "rightness", or "integrity") ${ }^{1}$ in the text of Meng-Zi. ${ }^{2}$ I argue that the current interpretations of this virtue get only part of the truth and neglect an important feature of it: its reliance on a social scheme to receive content. Partly because Meng Zi (孟子) is frequently discussed in contrast to Xun $\mathrm{Zi}$ (荀子) who emphasizes the rule-following aspect of ethical life, his insight about social norms and how they relate to virtue is ignored. My account of $y i$ highlights that aspect of his thought. Besides, a set of respectful sentiments - sentiments that involve giving priority to the significance of others by serving them - plays an important role in the motivational structure of $y i$.

ZHANG, MENG: Indiana University at Bloomington, USA. Email: zhang319@iu.edu

\footnotetext{
${ }^{1}$ Due to the multi-dimensionality of $y i$, I keep this term untranslated.

${ }^{2}$ All translations of the text are from Bryan W. Van Norden (trans.), Mengzi with Selections from Traditional Commentaries.
} 
Backed up by a rich psychological account, Mengzian yi incorporates the normative force of social norms without reducing itself to mere rule-abidingness. In the conclusion, I suggest one potential contribution of Meng Zi's account of $y i$ to contemporary virtue ethics: it points to a way to conceptualize virtues that have ruleconformity as a component - which I call "rule-related virtues". Equipped with full analyses of rule-related virtues, virtue ethics can guide actions more easily without giving up its central commitment to making moral evaluations in terms of the inner state of the agent. I want to emphasize that this paper focuses on Meng Zi; I am open to the possibility that other Confucian thinkers understand yi differently.

\section{THE PROBLEM OF YI IN THE MENG-ZI}

In this section, I identify two influential approaches to understand yi. Both capture part of the truth but are vulnerable to interpretative and philosophical problems.

One common way to interpret $y i$ in traditional commentaries and contemporary scholarship is to understand it as "appropriateness ( $y i$ 宜)" ${ }^{3}$ For example, Roger Ames holds that $y i$ "is an achieved sense of appropriateness that enables one to act in a proper and fitting manner, given the specifics of a situation" (Ames 2011, 205). Following Ames, James Behuniak understands $y i$ as "a social sensibility that enables one to behave in a fitting manner" (Benuniak 2005, xxvi). As a characterization of one aspect of $y i$, such claims are unproblematic, but as a full analysis, this account is inadequate since it over-expands the scope of the virtue of $y i$. Think of a case in which a civilian thrown into the battlefield escapes out of fear. Suppose that she feels the right amount of fear and reacts to it correctly (here, to escape). What she does is appropriate, but the virtues shown by her action are prudence, alertness, and self-control (by not being panic) instead of $y i$ as Meng $\mathrm{Zi}$ understands it. In other words, "appropriateness", standing alone, is too thin to capture what is definitive about $y i$. To be $y i$ is certainly to be responsive to features of the context. But Meng $\mathrm{Zi}$ also claims $y i$ to be internal to human nature $(6 \mathrm{~A} 4,6 \mathrm{~A} 5)$, that is, $y i$ is also a manifestation of some inner quality of the agent. ${ }^{4}$ Characterizing the content of $y i$ solely by referring to contextual factors, this account overlooks the rich materials about the psychological constitution of a yi person in the text. $^{5}$

\footnotetext{
${ }^{3}$ See Zhu Xi (1933, 28), Jiao Xun $(2015,754)$, and Cheng $(1972,276)$.

${ }^{4}$ Behuniak $(2015,38)$ and Chong $(2002,103-4)$ argue that Meng Zi refutes the internal-external distinction and does not argue for the internality of $y i$. It is unlikely that Meng Zi's attitude to this distinction is a total rejection, even if he is dissatisfied with Gao Zi's and Meng Jizi's way to talk about internality and externality. In 6A6 he explicitly says that the virtues are "not welded to us externally 非 由外鑠我也.”

${ }^{5}$ Among the interpreters who understand $y i$ in terms of appropriateness or fittingness, Kwong-loi Shun shows a tendency to specify what kind of standards $y i$ actions are supposed to fit. For him, $y i$ "as an ethical attribute of a person has to do with a firm commitment to ethical standards" (Shun 1997, 62). I think the term "ethical standards" is still too general. All virtues by definition lead to actions that are appropriate according to ethical standards. To say that $y i$ is a commitment to acting according to ethical standards interprets $y i$ as an all-encompassing virtue, making us wonder why other virtues are still needed.
} 
Based on Meng Zi's claim that "the feeling of shame and dislike is the beginning of $y i$," Bryan Van Norden states that $y i$ "is a disposition to disdain or regard as shameful certain character traits and the actions that would be characteristic of them" (Van Norden 2007, 270). Van Norden indicates that here the tendency to disdain or to regard as shameful should not be understood in the conventional sense; rather, it is a disposition to have an unpleasant feeling when one recognizes the character flaws of their own or of those with whom they identify and to have appropriate emotional and behavioral reactions to this recognition. (Van Norden 2002, 52) This view is challenged in less moralized readings offered by interpreters like Jane Geaney (2004) and Seok (2017). There is no space to examine the details of their disagreements. But at least two lacunae can be found in the moralistic reading. First, not in all instances of shame the agent has appropriate emotional or behavioral reactions (3B7, 2A9). Secondly, not all instances of shame are triggered by the recognition of character flaws (1A5, 4A8, 2A7).

In my view, the feeling of shame in the Meng-Zi is no more than shame in general - the negative feeling toward oneself after one's inferiority in some aspect is exposed through the attitudes of an other. Such exposure happens when the agent perceives a discrepancy between her self-regard and an other's evaluation of her. The "other" can be actual or imagined, and the latter paves the way to the development of an intrapsychic moral authority. The tendency to feel shame contributes to the demarcation of a moral dimension of life that informs the agent about what is truly base and to avoid, but it does not alone constitute the dispositional core of yi. Meng $\mathrm{Zi}$ insightfully claims shame to be only the "beginning" (duan 端) of $y i$, not $y i$ itself. Not only an unmoralized sense of shame (like the shame over one's poverty) but also a moralized one is inadequate as the motivational core of $y i$ actions. A $y i$ person may have a heightened repugnance to the defects in her character, but this sensitivity should not be what typically motivates her to act in $y i$ ways. For one thing, insofar as she is a yi person already, she should not have numerous enough character defects to trigger her yi motives so that she acts frequently in $y i$ ways. For another, in many circumstances, the concern about one's character is the wrong kind of reason to qualify an action as virtuous. There seems to be something particularly other-regarding in the virtue of $y i$ that goes beyond the concern for one's own moral status.

In sum, both approaches discussed above capture only part of what $y i$ consists in: the first approach grasps the context-sensitivity of this virtue, but is too thin to distinguish this virtue from acting properly in a general way and leaves unsaid the characteristic feelings that constitute a $y i$ motive. The second approach specifies what mentality this virtue requires, but confines the characteristic feelings of $y i$ to a too moralized understanding of shame. As I will argue below, both fail to pay enough attention to the reliance of $y i$ on a social scheme as the general regulation of behavior to receive its content. In the next section, I will lay out the two faceted-structure of $y i$ by examining different usages of the term " $y i$ " in the Meng-Zi. This structure calls for a more rigorous analysis of Meng Zi's moral psychology to identify the dispositional

Insofar as Meng $\mathrm{Zi}$ bothers to name different virtues, more needs to be said to distinguish yi from other virtues. Thanks to an anonymous reviewer for bringing my attention to Shun's account. 
core of $y i$, and that can be done by looking into a relatively ignored emotion in the Meng- $Z i$ - respect.

\section{TWO FACES OF YI IN THE MENG-ZI}

One difficulty to fully analyze $y i$ in the Mengzian context is due to the structure of $y i$. On the one hand, $y i$ has an intimate relationship with both the physiopsychological factor of qi (2A2) and one's inborn tendencies to feel, and thus is treated as a disposition. On the other hand, $y i$ is involved in the discussion of the social order which determines the correct way to conduct a wide range of activities from getting married to taking governmental positions. ${ }^{6}$ In several instances, the latter aspect of $y i$ is so prominent that $y i$ is paralleled with the term ritual ( $l i$ 禮) which relates to a codified norm specifying proper behaviors. In the rest of this section, I offer textual evidence to illustrate the two aspects of $y i$, and suggest that $y i$ as a disposition has abiding by norms as a component. ${ }^{7}$

\section{Yi as A Disposition}

In many places “ $y i$ " refers to an aspect of personality. In 4B19, Meng Zi praises Shun's acting out of benevolent and $y i$ intentions instead of simply following the requirements of benevolence and $y i$. That is to say, a truly $y i$ person as Shun is, when acting in a $y i$ way, expresses a genuinely $y i$ intention, rather than following rules in the purely behavioral sense. In 7B37, Meng Zi says he hates slyness (ning 侒), here apparently a vicious disposition, which sometimes is confused with $y i$. In 4B5, 1A7, and 3B9, $y i$ is paralleled with the character trait of benevolence, a virtue rooted in one's compassionate heart. As a quality of one's personality, yi can be possessed by a person, and it brings to the possessor joy $(4 \mathrm{~A} 27,6 \mathrm{~A} 17)$ that is not lost together with external goods (7A9). Moreover, $y i$ is rooted in the inborn affective capacities of humans, not forged upon from outside (6A4, 6A5).

\section{Yi and Norms}

$Y i$ as a disposition is only part of Meng Zi's usage of the term. There are places where $y i$ is closely linked to inherited norms that coordinate relationships. For example, in 7B2, Meng Zi says that there is no $y i$ war in the Spring and Autumn Annals, because the norms of war stipulate a war to be rightfully waged only when a state of a higher rank attacks its subordinate, while the wars in the Spring and Autumn Annals were waged between states of equal rank. Here $y i$ has nothing to do with the disposition of any person. What $y i$ is depends on the widely accepted rules regarding military affairs. Not only military operations but also economic arrangements can be $y i$ or not $y i$. In $3 \mathrm{~B} 8$, when asked by a counselor whether he could wait until the next year to tax at the proper rate, Meng Zi responds that if one sees the current taxation as not-yi, one should not wait until the next year to stop it. In 7A33, he says that "To take something that one

\footnotetext{
${ }^{6}$ This aspect of $y i$ in the Meng-Zi is similar to the primary meaning of $y i$ in the Xunzi analyzed in Hutton 1996, 2015.

${ }^{7}$ For a philological and historical examination of the two dimensions of $y i$, see Jia and Kwok (2007).
} 
is not entitled to is not $y i$." Here what $y i$ is depends on the norms that regulate the distribution of material goods.

Even in places where $y i$ sounds like a disposition, it is sometimes defined in terms of an order that specifies role-specific obligations. In 7A34, Meng Zi first admits that the hermit Zhong $\mathrm{Zi}$ has limited yi since he would refuse people's not-yi offering of a state. But then he immediately claims Zhong Zi's yi to be trivial, because "nothing is greater for a human than the relations between relatives, ruler, and minister, or superiors and inferiors." By refusing to fulfill his familial duties and the duty of a scholar-official, Zhong Zi loses the greater yi. In 3A4, Meng Zi says that it was the common $y i$ of the world (tian-xia-zhi-tong-yi 天下之通義) that the people laboring with their hearts govern the people laboring with their strength. The "common $y i$ " seems to refer to an overarching framework of the division of labor in which the whole human community is organized. In $1 \mathrm{~A} 3$, Meng Zi says that to realize the Kingly Way, the ruler should provide education and advocate the $y i$ of filial piety and brotherliness. Here $y i$ seems to refer to the norm specifying role-specific duties in familial life. ${ }^{8}$ In those examples, yi relates to a certain norm, order, or model that entails obligations. It has less to do with the disposition to feel and to be motivated in a certain way than with duty-entailing norms; it is something that can be violated (fan 犯) like punitive laws (4A1).

The norms presumed by $y i$ in the instances cover norms of different kinds: economic policy (3B8), norms on military and diplomatic matters (7B2), on property (7A33), social order (3A4), and familial duties (1A3). From today's perspective, those norms look so heterogeneous that one may doubt whether $y i$ is simply the state of affairs in a well-governed society. Yet I think one feature shared by the norms presumed by those instances of $y i$ is that they specify widely recognized role-specific duties backed up by established schemes. ${ }^{9}$ Given that the early Chinese society is permeated by the regulation of rituals, to a large extent the norms presumed by $y i$ overlap with rituals. Indeed, the binomial term of $l i-y i$ (禮義) appears no less frequently than benevolence and $y i$ (ren-yi 仁義) in the Meng-Zi (1A7, 7B12, 1B16, passim). ${ }^{10}$ When asked about how his refusal to meet with the various lords is $y i$, Meng $\mathrm{Zi}$ offers examples of ancient worthy people refusing to meet certain lords because they were not ministers. The

\footnotetext{
${ }^{8}$ The text is 謹庠序之教，申之以孝悌之義。The $y i$ here can also mean “meaning”, but unlikely so, since it should not be a problem for a competent user of the Chinese language at that time to identify what the terms "filial piety" and "brotherliness" mean. What needs to be taught or advocated are the obligations entailed by filial piety and brotherliness.

${ }^{9}$ I want to emphasize that "established schemes" are indispensable. It is tempting to think that a person's place in a relationship alone determines her duty in that relationship. But in most cases, it is not the relationship per se, but the socially recognized (sometimes legally sanctioned) norm regulating that relationship that determines one's duty in it. For instance, in many societies, children do not have the duty to support their biological mother if the latter is not involved in any way in nurturing them. The biological relationship of the woman and the child does not by itself entail a duty.

${ }^{10}$ For the close association of $l i$ and $y i$ in a larger Confucian context, see Ames 1987, 98-9.
} 
ancient people are $y i$, because their behavior conforms to the ritual that only ministers (instead of commoners) meet the rulers (3B7). ${ }^{11}$

\section{The Disposition of Yi Having Conformity to Norms as A Component}

From the cases above we can see that some references of " $y i$ " involve norms that regulate collective life. Then how does this aspect of $y i$ relate to $y i$ as a disposition? One option is to view a person's being yi or not-yi as totally dependent on whether they constantly act according to norms; $y i$ as a disposition is parasitic to norms.

Yet this understanding of $y i$ encounters two interpretative difficulties. First, it cannot explain in what way $y i$ as the propensity to be subject to norms is "internal" to human nature as Meng $\mathrm{Zi}$ so rigorously argued. In 6A5, he states that external rules determine the way in which one's respect is expressed. Just like the external environment (summer or winter) indicates what to drink to quench one's thirst (cool water or hot broth) but the need to drink is from human physicality, norms determine the way to express one's emotion, but there needs to be an emotion to be expressed in the first place to qualify an action as virtuous.

${ }^{11}$ Meng $\mathrm{Zi}$ articulates his thought primarily in terms of virtue and says less about norms of different kinds. Regarding the relation between the norms presumed by $y i$ ("yi-norms" below) and ritual norms, I have two clarifications:

First, I do not take the $y i$-norms and rituals as norms regulating different spheres of life like legal codes and etiquette in our society. A set of $y i$-norms and a set of ritual norms may regulate the same sphere of social life (like in 6A5). They differ in their codifiability and concreteness. Yi-norms are uncodifiable and in many circumstances need the codifiable rituals to be carried out. For example, yi requires a minister to assist the ruler to govern well. Ritual specifies the concrete manners for a minister to do that: how to speak in the court, what style to use in paperwork, how to accept or decline a position, etc. Given the penetration of ritual in all relationships in early China, the distinction between $y i$-norms and ritual is more in concept than in practice. The execution of role-specific duties is more often than not regulated by ritual. Hence the frequent parallel of li-yi mentioned above.

Secondly, it is tempting to say that rituals are conventional codes to be disregarded when more important values are in danger (e.g., 4A17), while $y i$ is overriding and should never be compromised (e.g., 6A10, see Shun 1997, 57 for this view). However, remarks like 4B6 complicates the issue. 4B6 says: “a great person will not engage in 'propriety' that is not propriety, or ' $y i$ ' that is not $y i$ 非禮之禮, 非義之義，大人弗為.” By ““propriety” that is not propriety”, perhaps Meng Zi means actions that have external conformity to ritual codes but are against the value supposed to be protected or expressed by those codes (e.g., refusing to touch one's drowning sister-in-law is against the idea of giving due treatment, including cherishing her life, to one's sister-in-law). A great person should not do that. If that is the case, by " ' $y i$ ' that is not $y i$ ", in a parallel way, Meng Zi means that behaviors that conform to $y i$ norms (e.g., a minister defending one's ruler) may be against the value that the relevant $y i$-norm is supposed to protect or express (e.g., defending the Tyrant Zhou against King Wen is against the value that the $y i$ of a minister should promote - good governance). If this reading is correct, 4B6 implies that in extreme cases yi-norms can also be overridden.

The last point leads to the question of what exactly is the value that undergirds $y i$-norms. Unfortunately, Meng $\mathrm{Zi}$ does not have a direct answer. His two versions of the origin story of social order, 3A4 and 3B9, are both told in very broad strokes and serve more local purposes. There is no space to attend to the details of them, but I think one message (though not the central message) conveyed by them is that norms are established to promote a peaceful and prosperous livelihood for humans by meeting their physical and social needs.

Thanks to an anonymous reviewer for requiring me to make the clarifications. 
Secondly, understanding $y i$ as parasitic to norms ignores the rich materials in the $M e n g-Z i$ about a cluster of sentiments involved in the disposition of $y i$ - the respectful sentiments. Besides 6A5, there are other passages linking $y i$ and respectful sentiments. ${ }^{12}$ In 7A15 Meng Zi says definitively that "revering one's elders is $y i . "$ When specifying the ideal of the five relations, he says "Between ruler and ministers there is $y i$ " (3A4) and in 2B2, Jingzi (with whom he agrees on this point) says that "ruler and minister emphasize reverence" - the expression of reverence marks the $y i$ between ruler and minister. Such frequent parallels suggest that the agent's feeling certain respectful sentiment is characteristic for $y i$ motives.

Those materials call for a more nuanced account of the mental state that undergirds $y i$ motives. Meng Zi uses different terms - respect (gong 恭), reverence (jing 敬), esteem (zun 尊), honor (gui 貴), and to follow (cong 從) - to denote the attitudes constitutive to $y i$ motives. For my over-arching purpose, I use "respect" as an umbrella term to refer to those respectful sentiments. I am not interested in differentiating one's respectful feeling toward one's elder brother and that toward one's ruler. Rather, I aim to portray what for Meng $\mathrm{Zi}$ is the right kind of mentality behind one's voluntary following of social norms. Respect is not the only emotion involved in $y i$. After discussing respect, I will briefly explain the relationship between respect and shame, and show how they together constitute the psychological core of $y i$.

\section{YI AND RESPECT IN THE $M E N G-Z I$}

Compared with other emotional capacities like the tendencies to feel commiseration and shame, the capacity for respect receives relatively less attention. Yet helpful discussions exist. Discussing respect and ritual propriety in early Confucianism, Sinyee Chan understands respect as "a serious frame of mind" that can have both persons and inanimate objects (Heaven, ceremonies, one's duties) as its object (Chan 2006, 229). Following Chan, Pengbo Liu proposes what he calls an "inside-out model" to understand respect. For him, Confucian respect is "rooted in certain virtuous attitudes and dispositions that constitute one's general way of dealing with the world and one's own place in it. Specifically, these attitudes and dispositions include, but are not limited to, seriousness, caution, modesty, etc." (Liu 2019, 54). I am in line with their reading. Yet more needs to be said about respect to distinguish it from other attitudes that also involve seriousness, caution, and modesty, such as sincerity (cheng 誠) or awe (wei 畏). Furthermore, I think a distinction should be made between respect in Confucius (孔子)' and Xun Zi's thought and respect in the Meng-Zi: for the former respect sometimes have inanimate beings as the object, for the latter respect is almost always toward a

\footnotetext{
${ }^{12}$ It is noteworthy that the sentiments involved in $y i$ are also the paradigmatic feelings associated with ritual propriety, but by now this should not surprise us, since we have seen that $y i$ and ritual are intertwined for Meng $\mathrm{Zi}$.
} 
person, which can be seen in Chan's own textual survey (ibid, 232). ${ }^{13}$ The personoriented feature of Mengzian respect is captured by Myeong-seok Kim who understands it as "an emotional sensibility responsive to "(1) a person's worth as a person, (2) a person's worth deriving from his social status or his role in society, and (3) a person's merit due to his ethical or political accomplishment" (Kim 2014, 244). I concur with Kim in taking Mengzian respect as a responsive attitude toward other persons, but as Liu rightfully observes, in Confucian respect, "no special emphasis is given to the inherent properties of persons as such... properties of [respect's] objects are highly relevant to how to appropriately express [respect] in a given context" (Liu 2019, 54). Following Chan and Liu, I take Mengzian respect as a mental state that manifests seriousness and caution but is not dependent on any universally observed properties in each individual; following Kim, I take it as person-responsive. My view is a synthesis of theirs: precisely because Mengzian respect is person-responsive but not responsive to universal properties like rationality, it calls for established norms to specify the features of particular persons to respect. In what follows, I argue that the definitive content of Mengzian respect is the attitude of prioritizing and serving (Section 3.1). Because respect involves the propensity to serve, its expression calls for the application of rules so that the proper way to serve can be discerned (Section 3.2).

\subsection{RESPECT: A PROPENSITY TO PRIORITIZE BY SERVICE}

Meng $\mathrm{Zi}$ does not define respect. But the instances of respect in the text show that it involves subjecting oneself by prioritizing another person and almost always motivates the agent to serve and honor that person. ${ }^{14}$ In 4A2, he says, "One who does not serve one's ruler in the manner that Shun served Yao does not revere one's ruler." In 4A1, when explaining the $y i$ in serving a ruler, he says, "To be demanding of one's ruler is what is called being respectful. To display what is good and inhibit what is bad is called

\footnotetext{
${ }^{13}$ The only place where jing refers to a serious frame of mind toward impersonal being is 5A6: "Qi was worthy and capable of reverently continuing the Way of $\mathrm{Yu}$ 啓賢, 能敬承繼禹之道. ” But even here there is a personal element: what Qi reveres is the way of the eminent person Yu.

The distinction between respect for persons and reverence as a general frame of mind is especially important because it pertains to a distinction between Mengzian respect and the Neo-Confucian reverence anchored in a deep appreciation of principle or pattern ( $l i$ 理). Stephen Angle argues that NeoConfucian reverence consists in "attending single-mindedly to a particular thing or matter before one, in all of its distinctness" including "being aware of the interdependence of that thing or matter with its entire context" (Angle 2009, 154). In my view, Mengzian respect may be compatible with the metaphysical assumptions of Neo-Confucians but does not presume or require them. It is worth exploring in a different work how respect for persons relates to facing the cosmos with solemnity.

${ }^{14}$ The purpose of the following two sections is to understand the idea of respect. I will draw on examples from passages about both $y i$ and ritual propriety. I do not think this confuses those two virtues. Two virtues may share the same mode of feeling as one component of each and differ in other aspects. For example, both parental love and friendship involve affectionate care but they differ in aspects such as that the former has a level of indulgence and sense of responsibility that the latter lacks. Indeed, it is implausible to assume that virtues and feelings have a strict one-to-one relationship. A full examination of ritual propriety is beyond the scope of this paper. It suffices to say here that it does not involve the concern about one's character that yi requires.
} 
being reverent." In those cases, respecting the ruler means serving him by carrying out the duties of a minister so that the ruler rules well.

Respecting one's family members also involves service. In 5B4 Meng Zi praises Shun's honoring his father (zun-qin 尊親) by serving him: “In being a filial son, nothing is greater than honoring one's relatives. In honoring one's relatives, nothing is greater than caring for them with the world." In 4A27 and 7A15, he defines yi as "following (cong 從) one's brother" and “revering one's brother" (7A15) respectively. A sort of submission to the elders is exhibited in yi motives.

It should be noticed that although cong is sometimes translated as "obedience," the submission Meng $\mathrm{Zi}$ has in mind is not an absolute one that demands the elimination of the agent's will. Cong's literal meaning is "to follow" and "to go behind." It can refer to the behavior of obeying someone's order, but in the Meng-Zi it appears frequently in describing people's attitudes in addition to or even instead of behavior. Moreover, cong appears in relationships less antagonistic than the word "obedience" implies - one in which a person's will prevails and the other succumbs. In 6A7 Meng $\mathrm{Zi}$ assumes that in terms of flavor, all people's tastes cong the famous chef Yi Ya, which cannot mean that they obey Yi Ya regardless of their own will. Rather, people appreciate Yi Ya's taste of cuisine and take his judgment as authoritative. In 2A2 Meng $\mathrm{Zi}$ says that sages will cong what he says if they arise again. ${ }^{15}$ In $3 \mathrm{~A} 2$, quoting the Records of Rites he asks people to "cong the ancestors" in mourning and sacrifice. In $1 \mathrm{~B} 15$ and $5 \mathrm{~A} 6$ he uses cong to describe people following the sage king. In 2A8 he praises Shun to have "put himself aside and cong others."

A shared aspect of those diverse usages of cong is to accredit significance to someone by giving them (and their opinions and claims) priority in consideration. Regarding good teachings, one's attitude is to follow and incorporate them into one's own behavior; regarding good people, to associate with them and recognize their authority in practical judgment. If asked, the attitude of cong can be backed up by reasons. In the ideal Confucian family, the elder brother is the model whom the younger can imitate. The maturity of the elder brother qualifies him as an exemplar for the younger. Thus the younger brother, reaching a certain age, would recognize that "between elder and younger there is precedence" and prioritize his elder brother in the supposedly ritually regulated family life. This does not mean that the younger brother can never oppose the elder. Meng Zi's description of the respectful attitude of the younger, as most of his other descriptive and normative sayings, is not a direct injunction of action. After all, Meng Zi praises the Duke of Zhou for correcting his mistake in trusting his elder brother Guan Shu who revolted (2B9). What gets praised

\footnotetext{
${ }^{15}$ For other places where cong is used as following instructions or an instructor, see 6B14, 7A32, 7A41.

${ }^{16}$ For literal uses of cong, see 1B4 ("To cong the current down and forget to return is what is meant by 'drifting.' To cong the current up and forget to return is what is meant by 'reversing'.") and 4A24, 25, 4B30, 31, 33, 5A2, 6A8, 6A16, 6B6, 7B26. Cong can also mean "to chase" (3A3). The term "cong-zhe 從者”, “people who cong”, can mean “attendant” (3B4) or “follower" in the sense of following another's teaching (7B30). Perhaps not all usages of cong are relevant to Meng Zi's specification of the mentality of $y i$. But by listing such diverse use of the term I want to show that cong is not "obedience" in its most common usage today.
} 
there is the duke's correcting his mistakes by attacking and punishing Guan Shu. In this case, no obedience whatsoever is mentioned. Submission is part of the mentality of following, but not in the sense of eliminating one's will. ${ }^{17}$ When indicating that $y i$ is to cong one's brother, Meng $\mathrm{Zi}$ is illustrating the respectful mentality involved rather than defining the behavioral aspect of $y i$.

It is tempting to think that respect is necessarily felt by an inferior toward a superior in a hierarchical relationship with social rank being the only determinative factor of one's respectability. But the text shows that multiple properties in persons call for respect. Meng $\mathrm{Zi}$ lists three such properties: "At court, nothing is better than rank. In the village, nothing is better than age. In assisting the world and nurturing the people, nothing is better than Virtue." (2B2) In different spheres of social life, different standards of respectability apply. Those standards can intersect with each other. In 5B3 Meng Zi illustrates several cases of the "esteeming the prestigious" (zun-xian 尊賢, those of lower rank respecting those of the higher rank due to their status) and “respecting the worthy" (gui-gui 貴貴, the high-rank officials respecting the worthy due to their competence and virtue) happening simultaneously. ${ }^{18}$ The $y i$ in such respectful treatments, as Meng Zi says, is "one." Every society is norm-laden and has established rules to regulate relationships. What features are relevant in respecting persons and how persons should be respected depend on what such norms say. Hence the second feature of Mengzian respect: it requires definite norms to regulate its expression.

\subsection{RESPECT AS A MOTIVATIONAL SENTIMENT CALLING FOR ACTION IN ACCORD WITH NORMS}

In addition to being a "frame of mind" or a mere mood, respect in the Meng-Zi is associated with motives to treat others in a certain way. In 7A37, Meng Zi says, "To care for someone without respecting him is to treat him like a pet," and indicates that “empty 'respect' without actuality (shi 實) cannot ensnare a gentleman." In the context of the Warring States period, "actuality" involves giving gifts appropriate to the status of the person according to ritual and offering him governmental positions according to his ability (see 5B3). In 5B4 Meng Zi says that when receiving a gift from someone of an honorable rank, it is disrespectful to examine whether the giver obtains the gift in a $y i$ or not- $y i$ way. As long as the presenting and acceptance of gifts are in accordance with ritual, the gift should be received.

This is surprising considering Meng Zi's concern about one's integrity and uprightness. Why a careful examination before receiving a gift is disrespectful? If something is obtained in a wrong, or even merely questionable way, isn't it better to

\footnotetext{
${ }^{17}$ Indeed, understanding cong as obedience creates an internal tension in the text. Chen Daqi (2016) believes that for Meng Zi cong-xiong means to “obey (聽從，遵從) one’s elder brother”. Understanding cong this way, he wonders how, while the core of $y i$ is to obey (one's elder brother) but the $y i$ toward one's ruler is to rectify, thus not obey, him. (40-1) My interpretation of cong avoids this difficulty.

${ }^{18}$ From this case we can see that respect for Meng $\mathrm{Zi}$ is mutual even in the strictly hierarchical relationships like between a duke and commoner.
} 
refuse it to maintain one's integrity? Instead of refusal, Meng Zi recommends a mindset of deferring and giving priority to others: in normal social interactions, to take oneself as entitled with the authority to judge other people's moral status is disrespectful; it is arrogant to put oneself in such imagined authority. Even though he thinks many people in his time do get involved in not- $y i$ due to a detrimental social regime, for him, the right way to deal with the situation is not to break social rules, but to reform not- $y i$ practices while staying within the norm as a larger whole. As he says in 5B9, yi is the path and ritual is the door. They provide reliable guidance for people to figure out how to express the proper attitude to others. Even Confucius, when reforming the society, does not take the risk of abandoning such rules.

Put into the context in which $y i$ is linked to various norms to express respect, the otherwise thin and uninformative aspect of $y i-y i$ as appropriateness - becomes illuminating. For Meng $\mathrm{Zi}$, the way to reach that appropriateness is to follow the norms that specify role-specific obligations widely accepted by the members in the community. In the case of parents, it is caring and supporting; in the case of rulers, honest advice; in the case of a scholar-official with whom one associates, exchanging gifts in accord with his status.

Note that Meng Zi's view should be distinguished from any rule-fetishism that takes rules as unconditionally binding. When the other side in a relation refuses to regulate her behavior by the socially accepted rules, the agent no longer has the obligation to abide by those rules. In 4B3 King Xuan of Qi speaks of the ritual that a minister should wear mourning clothes for a deceased ruler, complaining implicitly that people no longer do that in his time. Meng Zi responds that if the ruler does not treat the minister properly (putting the minister's admonitions into effect, listening to his teachings, assisting his trips, etc.) but on the contrary keeps obstructing the minister's work, the ruler does not deserve to be treated in accordance with ritual. Rules are not to be followed unconditionally.

In sum, Mengzian respect is the tendency to prioritize others in a relationship by serving and honoring them according to the norms accepted to regulate their relationship. As part of the psychological core of the disposition $y i$, it is inborn to human nature but calls for established rules to provide guidance regarding what specific treatment is owed to the respected.

\subsection{RESPECT, SHAME, AND YI AS A VIRTUE}

The previous account of $y i$ is compatible with pictures of $y i$ drawn based on the other feeling that Meng Zi links to yi, shame. Mengzian shame and respect are closely connected, if not textually, at least phenomenologically, since both feelings involves the sensitivity to the significance of others and the negation of self-assertiveness. ${ }^{19}$ Think of what defects of character may be involved in someone who commits not-yi by transgressing a norm. Not bothering to take heed of what is required in a relationship, they fail to respect the relevant persons in that relationship. They do not take seriously

${ }^{19}$ Shun (2013) also notices this. 
other people's claims on them - the claims that they should regulate their behavior by the shared norms as everyone else in the community. The disrespect shown in the nonperformance of one's duty entails an inadequate sense of shame. By ignoring the duty that community members expect them to fulfill, the not-yi person rejects the community members' status as stakeholders entitled to evaluate her, for their prospective attitudes, the indignation or disdain that the non-performance of duty would incur, do not feature in the not-yi person's self-evaluation. This is disrespectful since it is a symbolic communication that those attitudes do not count. It is at the same time shameless, since the not-yi person has an impenetrable self-conception that refuses to internalize the negative feelings toward them.

The connection between respect and shame is due to the structures of both. The feeling of shame is by nature intersubjective - feeling shame involves responding to the attitudes of others with a self-conception in mind. Such a response presumes some significance of others that the agent has to attend to. The feeling of shame has as a part of it the recognition of such significance by yielding to other people's expectations and demands, namely, Mengzian respect. Just as the ability to feel shame presumes some minimum yielding - some willingness to render oneself susceptible to the attitudes of others, the feeling of respect for Meng $\mathrm{Zi}$ involves prioritizing the other and thus "lowering" oneself. ${ }^{20}$ In recognizing the significance of others by putting oneself under their evaluation, the agent makes herself vulnerable to the potential harm that their attitudes can inflict on her self-regard. The capacity to respect is rooted in the sense of shame.

In sum, Mengzian yi as a virtue consists in accrediting significance to other persons and responding to such significance by subjecting oneself to them in ways specified by the social norms. $Y i$ is preconditioned by a sense of shame as sensitivity to the attitudes of others toward oneself and instantiated in voluntarily submitting oneself to the norms that specify the due treatment of others and oneself. By showing respect through the pertinent norms, a yi person protects her status against disdain. Respect for persons and the sense of shame mutually undergird each other and together constitute the psychological core of $y i$.

\section{RULE-RELATED VIRTUES AND ACTION-GUIDING IN VIRTUE ETHICS}

My concern so far is interpretative. To conclude my discussion, I explore the significance of the Mengzian account of $y i$ for contemporary virtue ethics: it shows a way to incorporate rule-conformity without giving up the central virtue ethical commitment - to account for the standard of morality in terms of the inner state of the agent. Giving due attention to established norms, virtue ethics would be more capable of guiding actions in practical life. My remarks below will be preliminary, and from

\footnotetext{
${ }^{20}$ This aspect of respect is captured by Liu who observes that by advocating respect, Confucians "remind us of the existence of potential sources of values, reasons, or most generally, considerations outside ourselves, which we, given our natural tendency of self-importance, tend to neglect, or at any rate fail to take seriously enough" (Liu 2019, 56).
} 
now on I discuss from a virtue ethical perspective. That is to say, I presume that constructive work in virtue ethics is worth doing without defending the validity and merits of virtue ethics against other normative theories.

To begin with, virtue ethics has been proposed as a radical departure from other ethical theories as it argues that character traits, not actions, are the primary object of moral evaluation. This approach is accused of being unable to guide actions since it replaces all questions of what action one should take with the question of what kind of person one should be. To see the problem, let's look at a standard of right action proposed by Rosalind Hursthouse: "an action is right iff it is what a virtuous agent would characteristically do in the circumstances" (Hursthouse 1999, 18). This thesis looks unproblematic as a theory of right action. If a prosecutor prosecutes a defendant out of malice, although he is not virtuous, he does the right thing. ${ }^{21}$ According to Hursthouse's view, the rightness of his action comes from his doing what a virtuous person would characteristically $d o$, but his character is defective because he is not motivated in a way in which a virtuous person is characteristically motivated. ${ }^{22}$

But it is hard to see how this standard of right action can help a non-virtuous agent deliberate what to do. A virtuous person (by definition) reaches the right conclusion, spontaneously or after deliberation. Virtues of character and practical wisdom (here understood broadly as the capacity to weigh and measure the relevant goods correctly) coordinate with each other and lead to a decision attuned to the particular situation. Such ability, however, is not available to the not-yet-virtuous mind. Without being virtuous or surrounded by virtuous exemplars, one simply does not know what a virtuous person would do in her situation. When formulating a theory of right action we can refer to what a virtuous person would characteristically do, presuming accounts of that are available. But in practical life, when an agent needs to deliberate, she is often puzzled, confused, or struggling. Deliberation - what a virtuous person would characteristically do when facing a tricky situation - does not lead to the right action for a non-virtuous agent.

To respond to this challenge, Hursthouse argues that ideas of virtues and vices generate prescriptions and prohibitions - what she calls "v-rules" - such as "do what is honest, charitable, generous" and "do not do what is dishonest, uncharitable, mean" (ibid, 36). Her account, however, is not clear about the status of the v-rules and how they feature in the practical deliberation of mature moral agents. As Eric Hutton points out, she introduces the v-rules mainly as a method of educating children, and does not mention them in her key discussion of the virtuous person's deliberation (Hutton 2015,

\footnotetext{
${ }^{21}$ This example is taken from Sidgwick by Michael Slote (2001).

${ }^{22}$ There are other views on the standard of right action. Slote (2001) argues that a right action is an action motivated by virtuous intentions (so the prosecutor in the example above acts wrongly). Svensson (2011) argues that virtue ethics should not focus on the right action. Swanton $(2001,2003)$ develops a view that shifts the attention from the inner state of agents to the effects of character traits so as to make room for right actions in the concept of virtue. I choose Hursthouse's formulation because (1) it retains a commonsensical way to evaluate actions (i.e., the prosecutor acts rightly but for bad reasons), and (2) as an account of right action it is formal. Hursthouse launches it together with a eudaimonistic understanding of virtue, but the account itself can be used as a standard of right action with the standard of virtue otherwise construed. I will say more about Swanton's approach below in footnote 25.
} 
120). Furthermore, the v-rules still look quite general to me. They seem to include rules of different kinds. Among them, there are rules whose application is highly flexible and a single infringement of which has a relatively small impact on the rightness of an action and the goodness of an agent: to be a generous person I should do what is generous, like giving five dollars to the soup kitchen. But if I do not, I am not doing anything wrong and may still remain an overall generous person if I am willing to help others often enough. In some other cases, however, rule-following has a greater sway on our moral evaluation. Think of a bookkeeper who presses hard questions to the manager to examine the company's financial statements. Even when behaving with all due respect, she may look uncharitable, demanding, and obnoxiously detail-oriented. But she is not; instead, she is careful, upright, and honest as a bookkeeper fulfilling the requirements of her profession. Rules in such cases count more than rules in the generosity case. By giving them due weight, we offer reliable practical suggestions to morally mediocre people in spheres of life where rule-abidingness is the primary rightmaking feature of an action.

Appealing to rules looks a dangerous move for virtue ethics. The gist of virtue ethics is to account for moral values in terms of virtues independently from other measurements of value (rule-conformity or utility for instance). To recommend people to rely on rules instead of moral exemplars looks like reducing virtue to rule-conformity, which reminds us of the lamentable image of a bureaucrat heartlessly following rules. I think such difficulty arises because when illustrating their theory, virtue ethicists tend to focus on virtues which are basically modes of feeling plus some discretion of practical wisdom (e.g., benevolence, generosity, courage). ${ }^{23}$ When accounting for right actions, they tend to appeal to the same set of virtues and let the rarely possessed practical wisdom do most of the deliberative work. If a different set of virtues, virtues that have rule-conformity as a component, are at their disposal, it would be easier for them to recommend the agent to figure out and abide by established rules where they are available without giving up the virtue ethical commitment. ${ }^{24}$ The practical recommendation, ultimately speaking, is still to do what a virtuous person would characteristically do, but the virtues involved here require the agent to follow the pertinent rules. ${ }^{25}$

\footnotetext{
${ }^{23}$ Hursthouse explicitly refuses to discuss justice and rights because in her eyes those vague concepts are less helpful than concrete virtues $(1999,6)$. To me, this is an unfortunate move where she misses the opportunity to discuss a set of most action-guiding virtues. Putting aside rights, justice as a virtue has been elaborated by generations of thinkers from Aristotle. If it looks vague, it is precisely because it presumes a social, legal, and political framework as a general scheme of action to which Hursthouse's version of virtue ethics does not pay much attention.

${ }^{24}$ In extreme situations, rules should be overridden, but only a fully virtuous person has the required wisdom to decide correctly when to break rules. Here we are talking about non-virtuous people who do not possess practical wisdom of that level. Furthermore, practically speaking, the more prevalent problem in our moral behavior is not that we stick to rules too rigidly but that we are tempted to break rules when we should follow them.

${ }^{25}$ This is to say that by highlighting the merits of the Meng Zi-inspired rule-related virtues I am not providing an alternative to Hursthouse's standard. I am emphasizing the significant role played by social norms that determine our role-specific duties.
} 
The Mengzian account of yi presents a promising way to characterize that set of virtues - what I call rule-related virtues. The two-faceted structure of Mengzian $y i$ strikes a delicate balance between the emphasis on the inner state of the agent and the attention paid to the schemes of action determined by institutions and conventions. Its rule-related aspect stresses the significance of social norms in guiding behaviors. Its dispositional aspect maintains the priority of the inner state of the agent by insisting that to qualify as $y i$, an action should be an expression of one's respectful feelings and the sensitivity of the demands of others. Many rules that Meng Zi takes for granted do not apply to other societies. But the structure of $y i$ can be used to characterize rulerelated virtues in a modern society such as justice, accountability (in team or organizations with regulatory frameworks), loyalty (to business partners), courtesy, etc. In this kind of virtue, the salient norms play the major right-making role in actions. For example, loyalty to business partners involves a certain amount of commitment to individuals just like loyalty in interpersonal relationships, but it has more to do with norms in the business in question such as information transparency, technology sharing, the adoption of protectionist strategies against rivals. Equipped with thick descriptions of rule-related virtues, virtue ethics is more ready to guide actions for non-virtuous agents: they (in fact, we) are recommended to follow the established rules where they are available.

\section{ACKNOWLEDGMENTS}

I am grateful to Michael Ing, Wenqing Zhao, and two anonymous reviewers for comments that have helped improve this paper. I have also benefited from the stimulating comments of the participants in the $13^{\text {th }}$ Midwest Conference of Chinese Thought held in Bloomington, Indiana, 2017.

\footnotetext{
Another promising virtue ethical account of right action is from Christian Swanton. According to her target-centered theory, "an action is virtuous in respect $\mathrm{V}$ if and only if it hits the target of virtue V," and "an action is right if and only if it is overall virtuous" (Swanton 2003, 228). Much could be said about this account, for the sake of space, I confine my discussion to the following point: This account would work if the targets of virtues could be specified, but I doubt if Swanton's theory of virtue has enough resources to do so. The specification of the targets of virtues eventually needs to appeal to the concept of virtue, which in Swanton's theory is "a good quality of character ...to respond to, or acknowledge, items within its field in an excellent or good enough way" (ibid, 19, italics added). But what counts as "excellent or good enough"? Is the hatred of humanity strong enough to motivate the prosecutor to prosecute the defendant but not strong enough to murder him good enough? How about certain obsessive-compulsive disorder that can do the same motivating work? I suspect that to answer such a question, we are led to the idea of flourishing that Swanton wants to do away with. I owe my thanks to an anonymous reviewer for suggesting me to make this clarification.
} 


\section{REFERENCES}

Ames, Roger (1987), Thinking Through Confucius (Albany, NY: State University of New York Press).

Ames, Roger, and Rosemont, Henry (trans. with intro.) (1998), The Analects of Confucius: A Philosophical Translation (New York NY: Ballantine Publishing Group).

Ames, Roger (2011), Confucian Role Ethics: A Vocabulary (Hong Kong: Chinese University Press).

Angel, Stephen C (2009), Sagehood: The Contemporary Significance of NeoConfucian Philosophy (New York: Oxford University Press).

Behuniak, James (2005), Mencius on Becoming Human (Albany: State University of New York Press).

Chan, Sin Yee (2006), "The Confucian Notion of Jing (Respect)", Philosophy East and West 56.2: 229-52. <https://doi.org/10.1353/pew.2006.0018>

Cheng, Chung-ying (1972), "On yi as a Universal Principle of Specific Application in Confucian Morality", Philosophy East and West 22.3: 269-80. <https://doi.org $/ / 10.2307 / 1397676>$

Geaney, Jane (2004), “Guarding Moral Boundaries: Shame in Early Confucianism”, Philosophy East and West 54.2: 113-42. <https://doi.org/10.1353/pew.2004.0004>

Hursthouse, Rosalind (1999), On Virtue Ethics (Oxford: Oxford University Press).

Hutton, Eric (1996), “On the Meaning of Yi (義) for Xunzi”, MA Thesis, Harvard University.

Hutton, Eric (2016). "Ethics in the Xunzi", in E. L. Hutton (ed.), Dao Companion to the Philosophy of Xunzi (Springer Netherlands), 67-93. <https://doi.org/10. 1007/978-94-017-7745-2_3>

Jia, Jinhua, and Kwok, Pang-fei (2007), "From Clan Manners to Ethical Obligation and Righteousness: A New Interpretation of the Term yi 義”, Journal of the Royal Asiatic Society, $3^{\text {rd }}$ Series, 17.1: 33-42. < https://doi.org/10.1017/S135618630600 $6547>$

Jiao, Xun (2015) Meng-Zi-Zheng-Yi 《孟子正義》[Rectifying the Meaning of Mengzi] (Beijing: Zhong-Hua-Shu-Ju).

Kim, Myeong-seok (2014), "Respect in Mengzi as a Concern-based Construal: How It Is Different from Desire and Behavioral Disposition", Dao 13: 231-50. $<$ https://doi.org/10.1007/s11712-014-9373-2>

Liu, Pengbo (2019), "Respect, Jing, and Person", Comparative Philosophy 10.2: 4560. <https://doi.org/10.31979/2151-6014(2019).100205>

Meng-Zi 《孟子》; trans. Bryan W. Van Norden (2008), Mengzi with Selections from Traditional Commentaries (Indianapolis: Hackett).

Seok, Bongrae (2017), Moral Psychology of Confucian Shame: Shame of Shamelessness (Lanham, MD: Rowman \& Littlefield).

Shun, Kwong-loi (1997), Mencius and Early Chinese Thought (Stanford: Stanford University Press). 
Shun, Kwong-loi (2013), “On Jing 敬: Thinking Through Tang Junyi on Chinese Culture in Diaspora", Chinese Studies 31.2: 35-62.

Slote, Michael (2001), Morals from Motives (New York: Oxford University Press).

Svensson, Frans (2011), "Eudaimonist Virtue Ethics and Right Action: A Reassessment", Ethics 15.4: 321-39. <https://doi.org/10.1007/s10892-011-9108-0> Swanton, Christine (2001), “A Virtue Ethical Account of Right Action”, Ethics 112.1: 32-52. <https://doi.org/10.1086/322742>

Swanton, Christine (2003), Virtue Ethics: A Pluralistic View (Oxford: Oxford University Press).

Van Norden, Bryan (2002), "The Emotion of Shame and the Virtue of Righteousness in Mencius", Dao 2.1: 45-78. <https://doi.org/10.1007/BF02856995>

Van Norden, Bryan (2002), "The Emotion of Shame and the Virtue of Righteousness in Mencius", in his (2007), Virtue Ethics and Consequentialism in Early Chinese Philosophy (New York: Cambridge University Press).

Williams, Bernard (1980), "Justice as a Virtue", in Amélie Oksenberg Rorty (ed.), Essays on Aristotle's Ethics (Berkeley, CA: University of California Press), 189-200.

Xu, Shen 許慎 (1975), Shuo-Wen-Jie-Zi 《說文解字》[Explaining Graphs and Analyzing Characters]. Incorporated in the Shuo-Wen-Jie-Zi-Gu-Lin-Zheng-BuHe-Bian《說文解字詁林正補合編》 (Taipei: Ding-Wen-Shu-Ju), vol. 10.

Zhu, Xi 朱喜 (1933). Si-Shu-Zhang-Ju-Ji-Zhu 《四书章句集注》[Commentary on the Four Books] (Beijing: Zhong-Hua-Shu-Ju). 